by twitching of the eyelids and mouth, jerkiness of the breathing, especially inspiration, or some strange movement or sound, and so the essential thing can be accomplished-the immediate removal of all coverings from the face before the convulsions have set in. Frame, towels, everything, are taken right away, and the air of the room given free access; any obstruction must be completely relieved, and a gentle stream of oxygen allowed to flow towards the mouth. In this way the $\mathrm{CO}_{2}$ will diminish as much as possible by natural means. Recovery from the anaesthetic, so delayed in most of these cases, is permitted to proceed, until it is utterly impossible to have the patient come round any more, when pure chloroform may be given in small quantities and by a quite open method, though, indeed, this will often not be needed. The success of this procedure depends on the promptitude with which the onset of spasms is foreseen.

A field for investigation is here; but the most important thing for the time being is that as many as possible should know how to recognize the condition and treat it.

\section{THE APPENDIX REFLEX.*}

$$
\text { BY }
$$

A. B. MITCHELL, M.B., B.Ch., F.R.C.S.I., SURGEON, ROYAL VICTORIA HOSPITAL, BELFAST.

The appendix reflex, giving rise to pyloric spasm, followed by hyperacidity and symptoms suggestive of gastric or duodenal ulcer, is now well recognized.

The object of this paper is to suggest that in certain subjects, with unstable nervous system, a diseased appendix may be the exciting cause of symptoms of an entirely different character. I propose to illustrate this suggestion by reference to a series of cases which have come under my observation, in most of which the possibility of an appendical origin had never been suspected.

CASE I.-Migraine.

In 1912 a country farmer, aged 45 , was sent to me with a view to operation on his stomach, owing to repeated attacks of vomiting. His history appeared to be a typical one of migraine. As long. as he could remember he had suffered from violent headaches associated with the appearance of spots before his eyes and followed by severe vomiting. At first the attacks occurred only two or three times a year, then once a month. When $I$ saw him they came once a fortnight. He wakened with them, and was completely prostrated for a whole day, and unfit to work on the following day. He had no history of abdominal pain at any time The stomach appeared normal. I regarded the case as one of migraine, and said I could not give any guarantee of relief by operation. We might possibly find a chronic appendix, but operation would be largely exploratory.

I saw no more of him for four years. He came back stating that his attacks had become intolerable. They now lasted four days. He was five days in bed. He had to sell his farm as he was quite incapable of looking after it. He asked me to "open him up" and see if anything could be done.

At operation, which was carried out through a right paramedial incision, admitting of a thorough examination of the whole abdomen, we could find nothing abnormal except a very large, chronically inflamed and distended appendix, dipping into the pelvis and adherent there.

He made an uneventful recovery. He had no recurrence of headache for a month after operation. When I last heard of him a year later, he still had occasional headaches, but they never lasted more than a day, and he was again farming.

I have no doubt whatever that if this man had had the appendix removed in early life the attacks of migraine would have disappeared completely.

\section{CASE II.-Migraine.}

Shortly after operating on Case I, in 1916, a school teacher, a lady aged 40, came to me complaining of steadily increasing migraine. Her attacks, which at first had been monthly, had now become weekly. They were very severe, and unfitted her for her duty for two days at a time.

All the usual investigations had been made. The eyes had been thoroughly tested, and reading glasses supplied, without relief. The uterus was normal in size and position, functions regular. Urine normal in every respect.

In view of the previous case I suggested the possibility of relief by operation, at the same time explaining that no guarantee could be given. She at once agreed, saying she could carry on no longer as she was.

* This paper was read before the Section of Surgery of the Royal Academy of Medicine in Ireland on February 18th; the discussion which
followed was published in the JoUnN.14 of March 19th (p. 517).
At operation we found (1) a well marked chronic appendix, adherent to the caecum; (2) a cholesterine gall stone, the size of a small pea, in an apparently healthy gall bladder.

The appendix and the gall stone were removed, and the gall bladder drained. She made an uneventful recovery.

Even after the operation, with knowledge of the pathological condition, we could elicit no history suggestive of either appendix or gall-bladder trouble.

I had a letter from her a year later informing me that she had now only a very occasional headache, which never interfered with her work.

\section{CASE III.-Migraine, with Glycosuria}

In January, 1919, I operated on a young medical man, whose own account of his case speaks for itself.

"For several years previous to the onset of glycosuria (1917) I had periodic attacks of severe headache, associated with in digestion and loss of appetite, but no vomiting. The attac's lasted from two to four days, and were always in the frontal region, on one side or other, but never both sides together. The most tender spot was the exit of the supratrochlear nerve from the orbit. At times I could not use my eyes for the pain.

"The attacks continued till you operated on me in January, 1919. I think you found a chronic retrocaecal appendix, which you removed. This was associated with some cholecystitis, so you drained the gall bladder for a few days.

"Since that time I have been practically free from headache. I am also quite free from glycosuria, and am on an ordinary carbohydrate diet."

\section{Case rv.-Cyclical Vomiting: Acidosis.}

Early in 1920 I saw, with one of our leading medical men a little girl, aged 10 . Since she was 2 years old she had sufferce from attacks of acidosis with violent vomiting, occurring every two or three months, as the result of which she was confined to bed for some days, but was always relieved by large doses of alkalis. She never had any definite abdominal pain till the attack in which I had seen her. She then had definite symptoms of appendicitis. Immediate operation was advised, but it was with considerable difficulty that her parents could be persuaded to have this done. They said she was serribly nervous, and the

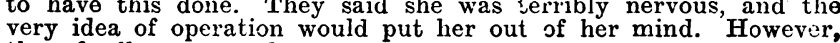
very idea of operation
they finally consented.

At operation we removed a distended, congested appendix. Recovery was uneventful. Her attacks of vomiting and acidosis disappeared completely. Her nerves quieted down. In a short time she became a normal child and has remained so ever since.

CASE v.-Cyclical Vomiting: Acidosis.

On January 1st, 1923, I saw a little girl, aged 6. She was guite well till $2 \frac{1}{2}$, years of age. She then began to have severe creased in frequency and severity until 1923, when $I$ saw her. They commenced with sneezing, running of the nose, then cough, lasting for a day, next day violent and persistent vomiting, which lasted twelve hours and completely prostrated her, leaving her greatly twelve hours and completely prostrated her, leaving her greatly attack, but no headache. She never had any abdominal pain, except some muscular pain after the vomiting.

A finger in the rectum elicited some tenderness high up when pressure was made with the other hand in the right iliac fossa $\vec{c}$ that is, a bimanual examination of the ileo-caecal region, which is so useful in children. Otherwise nothing could be made out. She was referred to a specialist for a thorough examination of the nose and nasal pharynx. He reported that there was nothing to account for her attacks. We accordingly operated, and removed a long, distended, corkscrew-like appendix. A month later she had one of her old attacks, then another slight one, after which they completely ceased. Her doctor reported on January $20 \mathrm{th}$, 1925, that she had remained perfectly well ever since.

Osler says: "In young children acetone acidosis (cyclical vomiting) may give difficulty in diagnosis from appendicitis. There may be severe vomiting, with abdominal pain, and the caecum may be distended and tender. The smei! of acetone from the breath and the urinary findings should distinguish." (Tenth edition, p. 533.)

I desire to suggest that in some of these cases appendicitis may be the real disease, the acidosis merely a reflex effect.

Appendicitis in children is very common, much more so than is generally recognized. I believe the majority of cases of so-called colic are primarily appendical, and that a large proportion of the cases of so-called chronic appendix which are met with to-day during abdominal operations have originated in early childhood. In the "nervous child" such an appendix may give rise to a variety of reflex symptoms, even in the absence of any local signs.

CASE VI.-Epilepsy.

In July, 1919, I was asked to see Mr. H., aged 37, who for years had been the subject of epileptic attaciss. In 1904 he had an attack of what seemed to have been appendicitis, and was 
laid up for a week. When I saw him he was the subject of chronic indigestion of the appendical type. He was taking bromide regularly to control his epilepsy.

Operation was advised (1) for relief of the indigestion, (2) in the hope that it might benefit the epilepsy. A large, distended, adherent appendix was removed from the ileo-caecal angle.

He made an uneventful recovery. He had no epileptic attack for six months after operation, and since that time the attacks have been much less frequent and less severe.

It seems reasonable to infer that if this appendix had been removed at a much earlier stage, before the epileptic habit had become confirmed, the result would have been much better, and possibly the disease might have been cured.

$$
\text { CASE vir.-Pctit Mal. }
$$

In May, 1922, I saw a boy, aged 10, a doctor's nephew, who had ior some year's suffered from attacks of petit mal, which were increasing in frequency. I was asked to see him owing to an attack of abdominal pain. We regarded the case as one of appendicitis, and advised operation. His mother at once pointed out that he had these nervous aitacks, and asked whether there would be any chance of the operation making them worse. Our reply was that there was every reason to hope it would make them better.

At operation we found a distended, obstructed appendix.

$\mathrm{He}$ made an uneventful recovery. The attacks of petit mal disappeared, and he is now a boarder at a public school, in excellent health.

Let it be clearly understood: I do not propose that every case of migraine, cyclical vomiting, or epilepsy should be submitted to an appendicectomy.

I do wish to point out that this group of cases, which may be classed with hysteria, neurasthenia, and certain cases of mental disease, have one feature in commonthat is, a nervous system so unstable that it is liable to be upset by some slight reflex stimulus which would not disturb a normal individual.

A thorough examination for an abdominal focus should be carried out in every instance. A misplaced uterus, or a movable kidney, will often afford an explanation, but $I$ venture to suggest that a diseased appendix will prove to be the exciting cause much more frequently than we have hitherto suspected.

When there is good reason for suspicion of that organ, appendicectomy should be seriously considered.

\section{THE TREATMENT OF RODENT ULCERS NEAR THE EYE. \\ BX}

ZACHARY் COPE, M.S., F.R.C.S.,

SENIOR SURGEON TO THE BOLINGBROKE HOSPITAL.

THE satisfactory treatment of rodent ulcers in the region of the cre and nose is sometimes a little difficult. For very small lesions the application of carbon dioxide snow may be efficient, in other cases the application of radium or treatment by $x$ rays may be recommended, but none of these methods is quite so speedy or efficient as excision, if that can be practised without causing deformity of the face.

If surgical measures are undertaken it is wise to remove the ulcer with a margin of at least half an inch surrounding it. If the ulcer is but the size of a threepennybit its remoral may leave a space necessitating a skin graft, for to bring the edges of the skin together will distort the eyelids or nose. The difficulty of applying a skin graft in the region of the inner canthus and ala nasi is readily understood. It is almost useless to apply grafts by the Thiersch method unless firm and equable pressure is maintained, and the difficulty of maintaining such pressure in this region is easily appreciable. Following the lines of the well known work of Lsser, which has been so skilfully developed by Gillies and others, I at first applied grafts moulded upon Stent's composition. This gave fairly satisfactory. results, but the material upon which the grafts were moulded was rather hard to press against the bony root of the nose, and if the mould was not absolutely perfect equable pressure over the whole area was not maintained. In searching for a suitable moulding material I thought of a substance which would be less hard when cold, but would enable pressure to be applied over the whole grafted area. Plasticine was therefore tried and proved suitable. This material was used because it was most readily obtainable, but ordinary artist's modelling clay would, I think, serve equally well, if not better.

The technique of the method is as follows. Under a general anaesthetic the ulcer is excised with half an inch of apparently healthy skin all round. Any bleeding vessel is seized by artery clips and oozing from smaller vessels checked by gauze pressure. Fine catgut may be used to ligature any larger vessel if necessary, but it is better to do without ligatures if torsion and forcipressure will suffice. Whilst the raw area is being made dry by pressure the surgeon takes up a piece of modelling clay which has been boiled in order to sterilize it, and breaks off a portion of a suitable size for the graft. It is then carefully moulded over the raw surface and contiguous surface of the root of the nose and upper or lower eyelid, and put aside whilst the outer aspect of the thigh is exposed for the purpose of cutting the grafts. The grafts are cut in the usual way by a razor or special knife, and are placed on the area of the clay previously moulded on to the raw surface, with their deep or raw surface outwards, so that when the mould is applied to the part of the face operated upon raw surface of graft meets raw surface of face. The grafts should more than cover the actual part of the clay which fitted the ulcer. The clay with grafts on it is carefully fitted on to the place from which the growth was removed and pressure is maintained by strips of strapping. A simple dressing is applied over this. The parts are not touched for about ten days; at the end of which time the dressing and clay can be removed. The grafts should then be firmly adherent and no raw surface be seen. A simple dressing may be applied and maintained in position by strapping for a week or two. The superficial scab of epithelium will gradually separate and leave a healthy depressed and firm scar. In the course of a few months this scar rises and restores an almost normal appearance to the site from which the rodent ulcer has been removed.

\section{MICROSCOPICAL AND CHEMICAL EXAMINATION : OF STOOLS IN YOUNG CHILDREN.}

ETHEL CASSIE, M.D., D.P.H.,

ASSISTANT MEDICAL OFFICER OF HEALTH AND MEDICAL SUPERINTENDENT OF THE CARNEGJE INSTITUTE; BIRMINGHAM; AND

URSULA COX, M.R.C.S., L.R.C.P., ASSISTANT MEDICAL OFFICER FOR CHILD WELFARE, BIRMINGHAM.

In order to ascertain what information might be gained by systematic examinations of stools in young children, careful observations were made during 1924 and 1925 on patients in the observation ward at the Carnegie Institute, Birmingham. As there was some variation in method and nomenclature during the early period, these notes deal exclusively with the cases of 1925 , when a more definite system had been instituted.

Chemical examinations have been made with the object of ascertaining the reaction, and the presence or absence, of occult blood; the microscopic examination has included Gram-stained films for the bacterial flora, and examination for pus, fat, etc.

Stools have been examined from cases of subacute and chronic enteritis; convalescents from enteritis; children with no intestinal disorder and with normal stools; cases of constipation; and breast-fed infants. All the patients were children under the age of 5 .

\section{(A) Chemical Examination.}

In the cases suffering from enteritis, 54 per cent. of the stools were acid, including all the more acute cases. Blood was found in 83 per cent. of the cases. Pus and epithelial cells were frequently found on microscopical examination of the wet preparation. As the patients improved the stools became alkaline, only 22 per cent. remaining or becoming acid. Blood was still found in 50 per cent. of the patients who had clinically quite recovered. Of the normal stools, 90 per cent. were alkaline, and blood was 